\title{
DNA Intercalation
}

National Cancer Institute

\section{Source}

National Cancer Institute. DNA Intercalation. NCI Thesaurus. Code C40492.

DNA Intercalation involves insertion by covalent linkage of a molecule into the doublestranded deoxyribonucleotide polymer between the internal purine and pyrimidine base pairs stacked one on another perpendicular to the double helix axis. 